\title{
Working with Cixous: The cleaner's grey drawings
}

Fig. 1 Author (2016). Surface 1: Swab 1

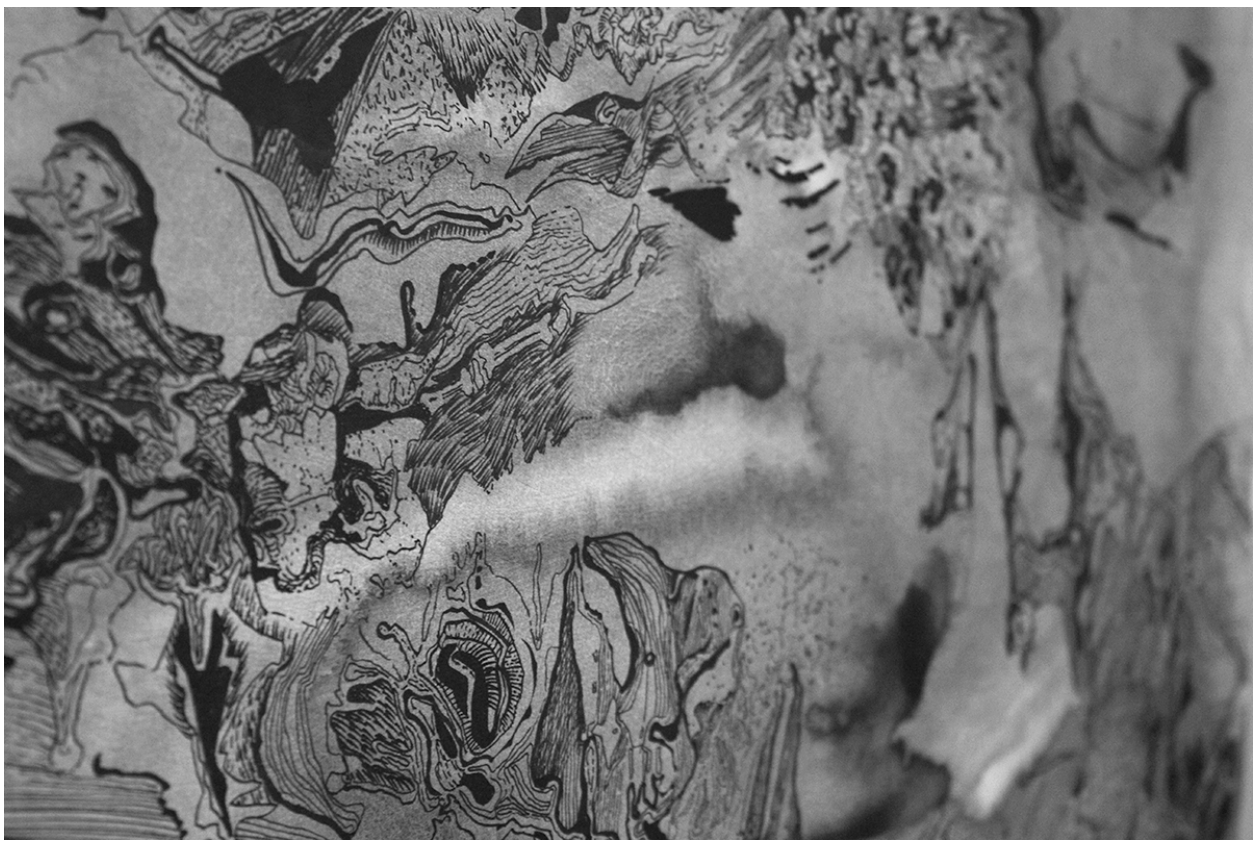

"We have to lend ears [...] to what is speaking, murmuring, signing around" Hélène Cixous said in a filmed conversation (2010) where she spoke of painters as recipients of messages from the past, and also from an arriving future running ahead. Elaborating on such insight, this essay deploys word pictures and drawn paintings to follow unconscious murmurs encountered in past acts of house cleaning, an undertaking that forestalls completion and engages with transformative material conditions. It is also an essay about an ending, although that is necessarily suppressed, for it is also an arriving future.

Contorted, the cleaner looked back and forwards to hear the conversations she had had with the houses in which she worked. Now elderly, she had been well trained in the space and formal conditions of rooms, operating outside notions of occupation, situated between life in the house and the life of the house; memories of that time would arrive without nostalgia. Originally the cleaner had been sent to work at a house in a dead-end street. Plain, blue and white, the house 
blocked off the end of the road. No front garden, no display to the street and entry through a wall into a private world. The cleaner arrived in a glazed space, two stories high with a passageway through to a tree filled garden and another much larger house beyond. Two houses, one urban and one suburban, meant negotiating the unstable histories of their combined interiors.

A shadowy figure barely there, the cleaner came to treat the two houses as knowing and aware, and always in need of physical attention. It was a sort of loving and disowning relationship that mimicked maternal gestures of attention and affection but which was also momentary, temporary. The cleaner had no 'proper' relationship with the houses but rather a dreaming, physical engagement, a compound of labour, boredom and fantasy. Stray hairs, pieces of skin, crumbs of bread, wrinkled cloth, dirt from the outside world, germs from interior regions - the housekeeper pretended that these things matter. She was conscious of working with emotions of homeliness, aesthetics of class, and a parody of medical science; her work seemed to be situated in a zone of property and denial.

Within the wall-like space of the house elevated above the garden, glass let sunlight into a small gleaming timber interior where dust mites were illuminated with the fluctuating breath of occupation. A similarly thickened luminous space was made vivid in the writing of Emma Cheatle as she imagined the sweeping gestures of the Maison de Verre housekeeper, cleaning away physical remnants of the gynaecology clinic and its operations. Cheatle wrote of visiting the building, "a long time later when I enter this room again, the now abandoned surgery, layers of dust shift. I am moved, unable to think. The thin, brittle glass appears a contradiction, soft and pulpy, like jelly or thick seawater. You are neither inside nor out, swimming in a translucent, thick glass space yet exposed, open" (2012: 110). A long way from Paris, black dust and thickened seawater would become the substances of drawings the cleaner produced later in life, having moved on from the houses for which she cared.

Fig. 2 Author (2016). Surface 1:

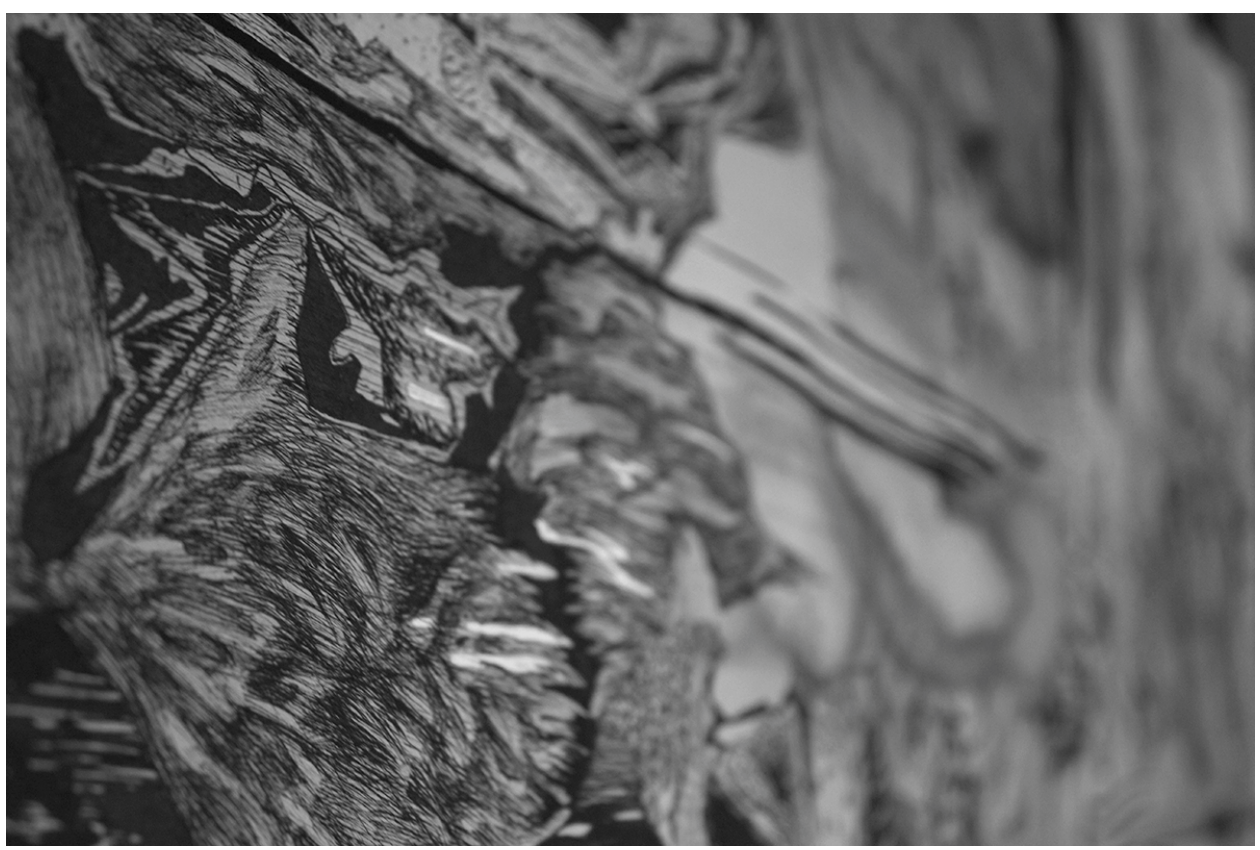


Cixous evoked cleaners when she noted that:

In order to live we busy ourselves casting off our sloughs. We pretend to be virgin and free from mortal remains and decomposition. We disown ourselves in bits and patches. Poor us, the denizens of heightened buildings, champions of denials, defenders of the Clean and Proper, we scaffold distances, walls, skyscrapers, classes, borders, in order to separate ourselves from our improper proper part. We furiously distinguish ourselves from our animality. We forget our natural mortality every day. (2012: 93)

Cleaners, chasing bits and pieces, might be seen to face up to the disowning we endlessly enact. The difficulty of removing mortal remains-hardened food scraps, traces of nail polish, and inadvertent splashes of Indian ink all beset the cleaner while a grey ring around the bath composed of soap fat and skin particles resisted her attentions. In her childhood she had been fascinated by the strange, purple-grey hue of an indelible pencil. The word 'indelible' itself seemed to be from elsewhere, suggesting access to another world. Marks from that pencil embellished surfaces intended to be blank and she recognised in them traces of illicit inscriptions persisting throughout her life. Indelible drawings grew in her imagination as she observed incised and burnished patterns in the houses she cleaned.

The film Koolhaas Houselife (2008) by Ila Bêka and Louise Lemoîne investigates the physical relationships between people, living or working, and the structures they occupy. Tracing the path of housekeeper Guadalupe Acedo as she cleaned the celebrated house in Floriac, Bordeaux, designed by Rem Koolhaas of OMA, the film collected her stories about the architecture and its occupants while the camera winds and swoops around the building following her work. The filmmakers talk of a building as a living body and wonder about the architect's primal fear of ageing. Perhaps the youthful perfection of a house occurs when it is detached from the architect and given to the client. Cleaners, however, following rituals prescribed as hygienic, register a gradual blurring of surfaces and the ageing sag of structure. Guadalupe Acedo knew the building intimately-in the film she is shown gathering and clutching curtains into human sized bundles while she talked of the sadness that followed the death of the man for whom thehouse had been built.

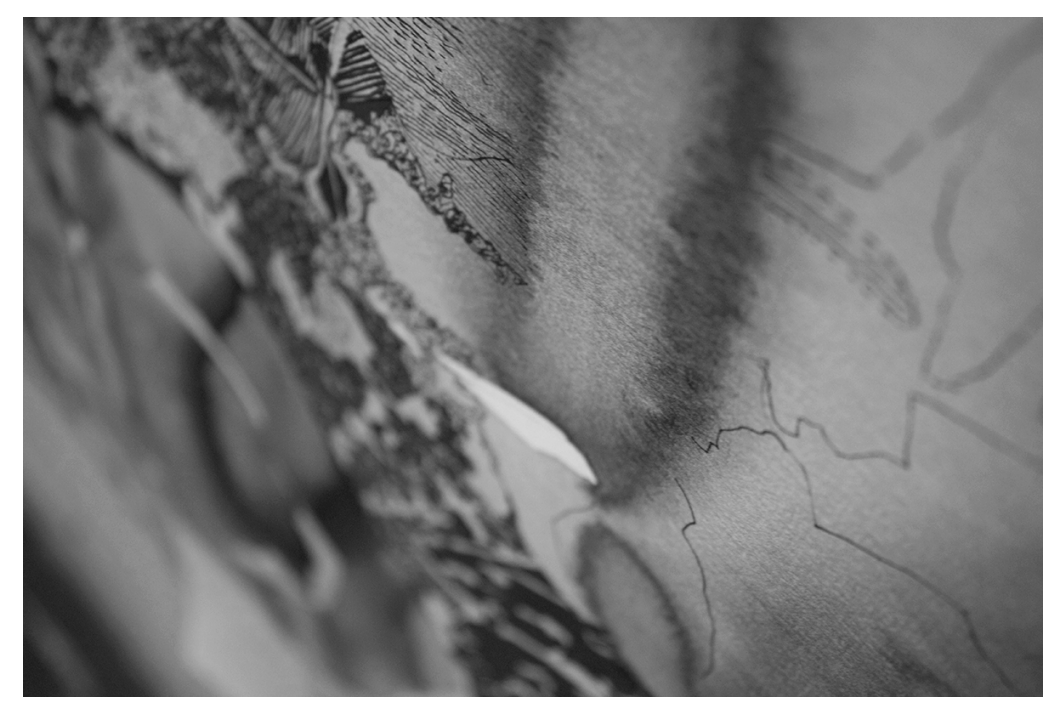


The house at Bordeaux has attracted essays and films that seek to undo the primacy of the static image as the representation of architecture (Colomina and Lleó 1998, Bêka and Lemoîne 2008, Ventura 2009). Each piece of writing and sequence of filming steps away from traditional, disciplinary representations of space and building and lets in personal stories, families and cleaners. The actions of Guadalupe Acedo make a physical and emotional pattern of the house-her hands spiralled upwards repeating the circulation of the occupants, she also talked of the laughter that filled the house, and then of that laughter's absence. She worried about the leaks. Leaks were also a source of contention and anxiety in the childhood home of the cleaner in Aotearoa/New Zealand. It was a commonplace occurrence met with plastic buckets decorating the floor of an upstairs hall; small fountains sparkled as they dripped into red bucket, blue bucket. Leaks might signal a lack of organization, money, an endless dissolution of the proper and discrete container of family life; they also indicate experimental joints, radical materiality, and a breezy permeability.

She remembered other leaking roofs in her life. To be without shelter, without security, is commonplace and fearful-the cleaner sleeps badly after watching the news and her dreams slip out. Creatures of the night leak through the ceilings, crawl out of the floorboards, slide from under mattresses, from behind the fridge, beneath the table. They change scale, cease to be invisible, and proliferate. Stirring in her sleep, the cleaner emulates Cixous's night time practice of recording dreams and draws the creatures on scraps of paper. Black and scratchy drawings bubbled with gentle laughter from the occupants of the houses, tainted by the bitter taste of lack and patterned by the variable shape of labour. She carefully makes and remakes the contours of the drawings, paying particular attention to surface conditions. At times tears drip onto the paper blurring the precision of the aesthetic intention. As Cixous suggested in the filmed conversation about writing, cleaning and drawing might also be seen as strategies "of repairing the biting of death into life" (2010). In the morning, the drawn creatures are flat and slightly strange, confirming Cixous' sense of her own writing where "everything that happens on the surface... is a surprise" (2010).

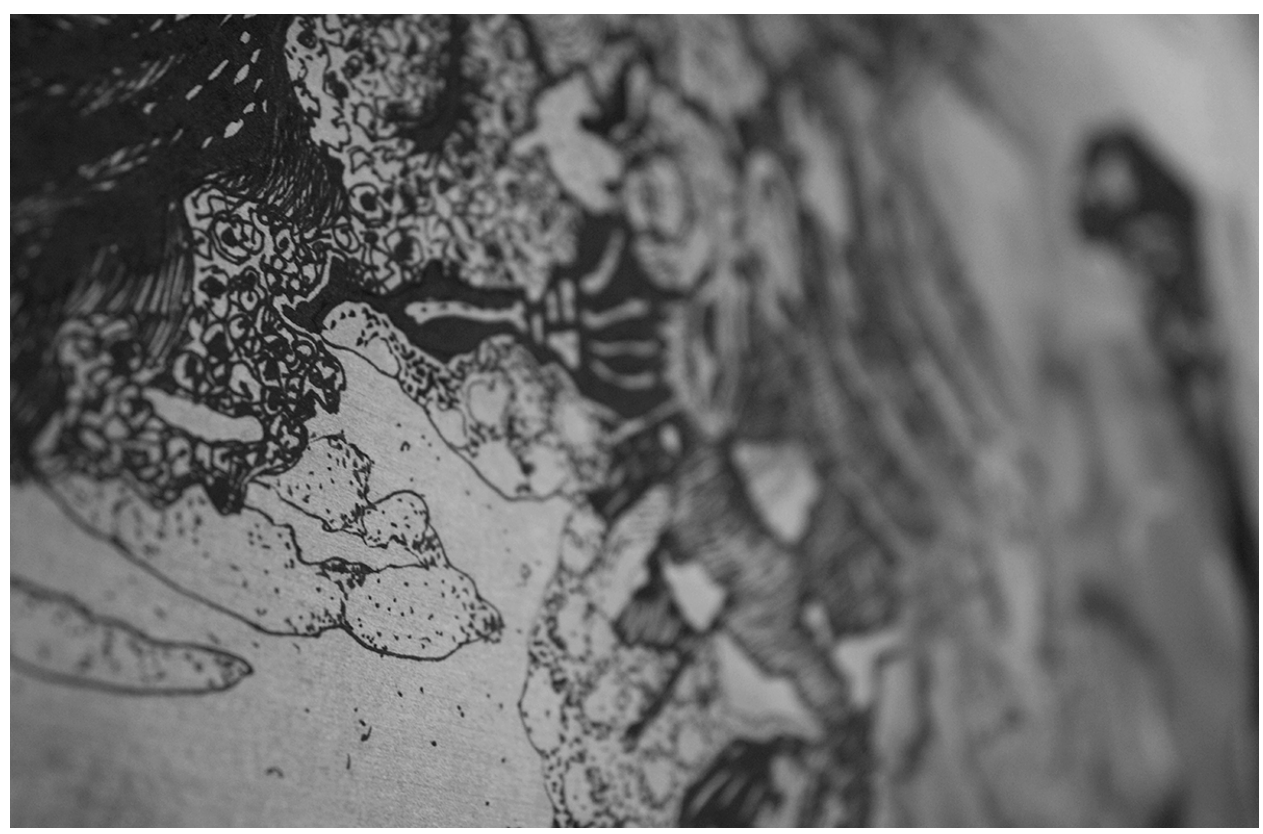


As she drew, the cleaner recognised in the night time visitants the concealed surface of her daytime labour. As Cixous explained " $[t]$ he drawing wants to draw what is invisible" (1998: 24). Dark drawings emerged endlessly, hovering in a shallow space of displaced attention; the cleaner imagined a clear surface but could not believe in the eradication of doubts, sorrows or the displaced. Accepting the sharp teeth of death, she cultivated only the appearance of obliteration. As a practitioner of surface attention and material care, the cleaner gave scant recognition to errant details, cultivating instead the variable continuities of the house.

Suppressing sticky secrets, small hand movements touch the house, and the drawing, repetitively and obsessively, going over the surfaces. With lines of movement, threads and combings, an unstable surface of a house is rewoven, births and deaths are recorded, acknowledged, felt and never eliminated; treacheries and pleasures are threaded through the surface constructions with ornamental repetitions. Her work slows as she drifts off into memories which are also part of the fabric that she makes. The physical labour, in its repetition and rhythms, is a song, a refrain, a mobile bubble of sound that momentarily calms the world (Deleuze \& Guattari 1987: 311). Singing to the house tunelessly, the pulsation of her throat binds her to the matter of the space; in tandem with the machines that growl across the floor, she is at once absorbed and detached.

Through her labours, the cleaner can induce only a pause in time and occupation. Her work creates an apparition of some original condition. Time falters as the mop moves back and forth, the pace and after-effects of physical action are regular, peristaltic. In an oblique alignment with the surfaces of the house, the cleaner constructs a space of hesitation in which to think, full of halting doubt and potential promise. Age is both denied and cultivated-polish builds up, patinas are preserved. In the cultivated surfaces lie shadowed aspects of occupation; echoes of disputes and words of love fail to register clearly and the rooms, in which so much was promised and given, have only an inkling of the future.

Blackness in the pot of ink, in the congealing surface that catches the light, is punctured by a nib that then drags across stained paper, trying to catch the fleeting visitants. Inklings are sharp, dark creatures partial in their definition; inklings of relationships and dreams that remain unfulfilled, or excesses expended and enjoyed, inklings born of idle observation. The drawings can only catch the barest black inkling of all the words, all the effort expended, the coming and the going of the interior. An arc of dirty water slashed across the stainless steel tub, drips flying, gritty. The cleaner gathered her belongings and left the house to others as the day ended. 
Fig. 5 Author (2016). Surface 1: Swab 5
Fig. 6 Author (2016). Surface 1: Swab 6

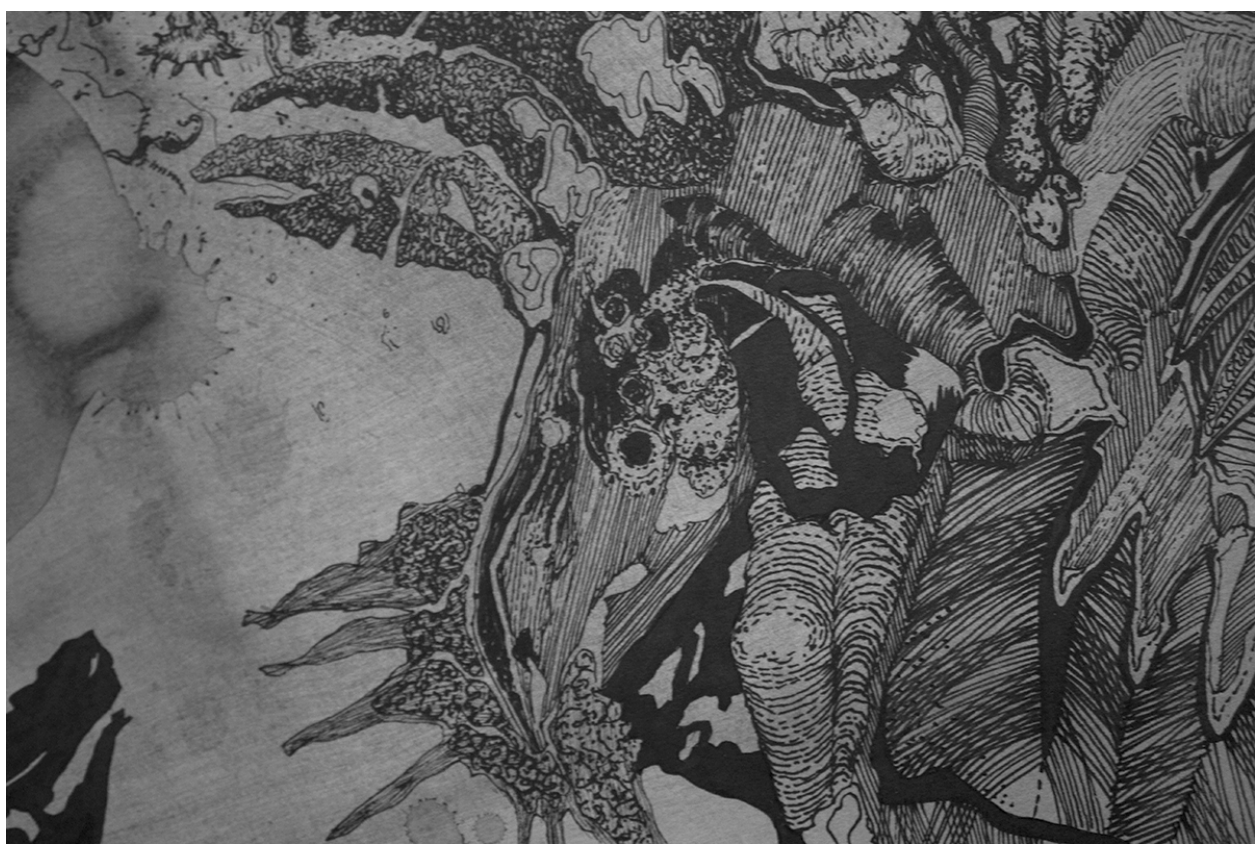

The odd culture of maintenance, reluctant to acknowledge change and uneasy with the release of time, seems to belong to the old world, to another world. As she walked home, the cleaner admitted to herself a minor tendency to celebrate the slow dissolution of the house; lightweight frames burn, decay flourishes in constant rain, carvings might be preserved but the house could blow away.

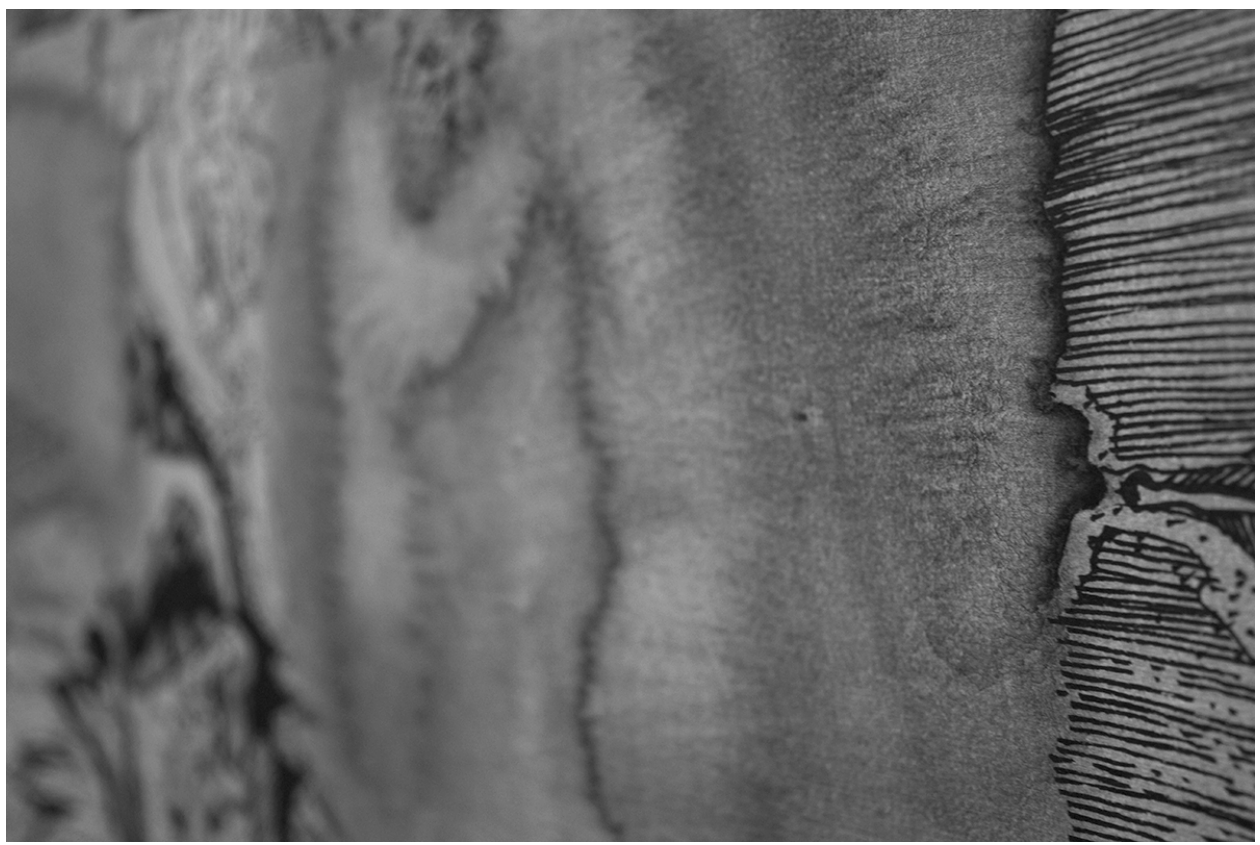

Maintenance might be said to demonstrate compliance and obedience to societal strictures on hygiene and conformity. It might also be a sort of ritual blood-letting-her hands were scoured and her knees ached. The cleaner knew of television programmes on hoarding and obsessive cleaning and recognised the thin border between her work and anarchy. Out walking one day she had seen another elderly woman haunted by the unseen who endlessly washed the 
gleaming weatherboards of her house. For Julia Kristeva knew it was "not lack of cleanliness or health that causes abjection but what disturbs identity, system, order" (1982: 4). Abjection marks, as she says, "the in-between, the ambiguous, the composite" (4). Hands scrabbling, lines of anxiety marked the face of the woman who tried to wash away the lines of gleaming weatherboards. At home now on a hill above the city, looking back down to the houses that she cared for, the cleaner washes creamy, thick paper with a mixture of mother's milk and Indian ink. She sweeps a broom across the skin, removing surplus tears. The stories of her day and the detritus that her work keeps at bay crawl across the surfaces of the houses that she draws but cannot inhabit. Joining together the drawings spread across the wall, there is no distinction between wallpaper and her work, which is never-ending.

Fig. 7 Author (2016). Surface 1: Swab 7

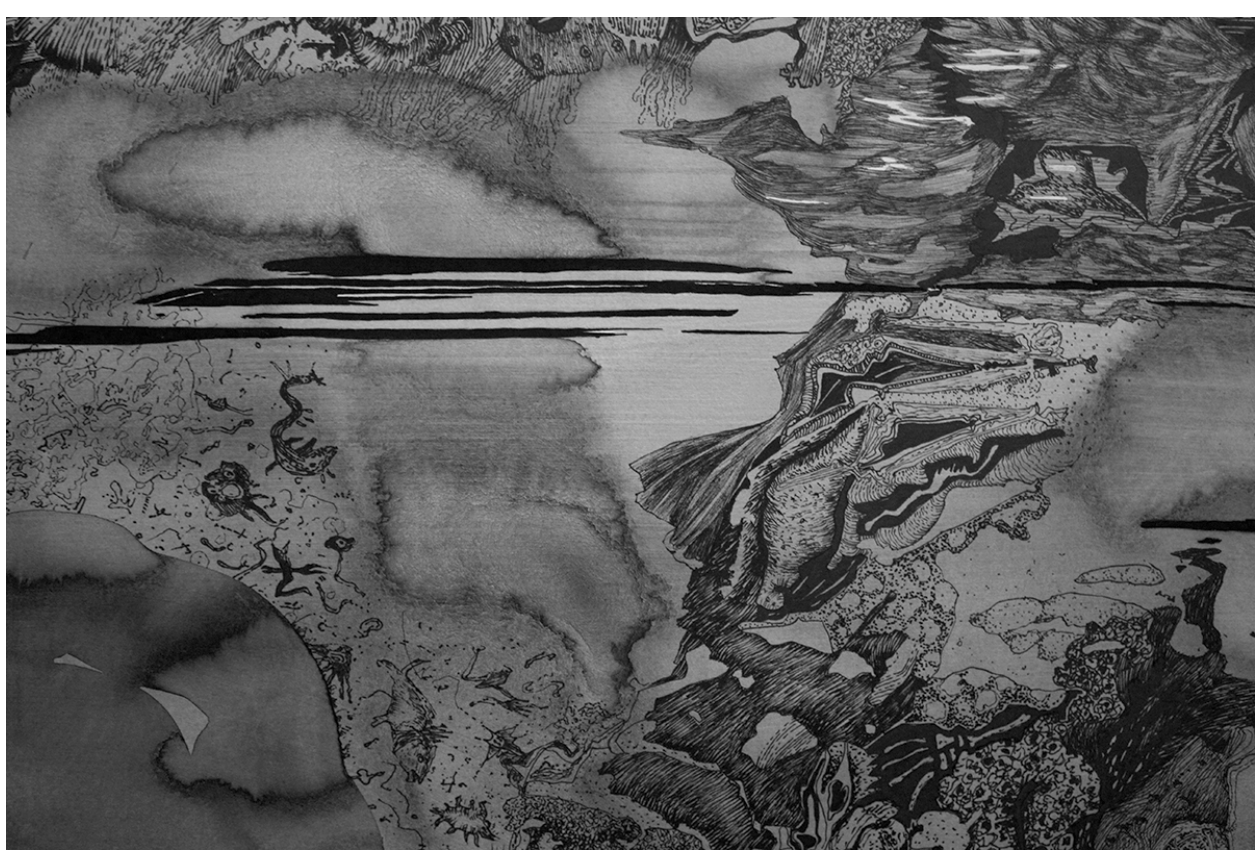

\section{Postscript}

This writing engages with a labour that, while mostly unrecognised, supports architecture and which itself is a form of drawing. Attentive to surface conditions, the material skin that engages with day-to-day life and death, cleaning is never about obliteration-in all its effort and repetitive labour, it allows a sensitivity to the emotional conditions of interiors and the residues of architectural occupancy. Are cleaners not painters who make works only to remake them again endlessly? For "what is a painter?", asks Cixous, but "[a] bird-catcher of instants" (1991: 104).

Writing here has been imagined as a net that envelopes and enfolds airborne moments passing by as sunlight catches dust particles. Caught in a brief curtailment of freedom, instants are drenched in the dampness of ink, making pictures which remain when the bird has vanished. Considered as swabs, as pathological and affectionate rubbings that seek to retain traces of substance, the drawings, 
paralleling the writing, have a tendency to accumulate all the problems and curiosities of decaying matter.

To clean the houses doubled in a dead-end street was to work with an architecture that was doubled and split between the past and the modern, between the suburban life of animals, small children and the city, a doubled condition reflecting the ambivalence of the cleaner who cares for, but cannot occupy, that to which she attends. Neither possessive nor entrenched in the operations of cleaning, the houses are understood to foster brushwork skills, soft techniques that are forms of inscription, accumulative, dreamy and material. Cixous, considering the writer Clarice Lispector's book Agua Viva, suggests that it "aims to write-paint, to work on the gesture of writing as a gesture of painting” (1991: 104-5). Undertaken in this piece of writing is a transitional negotiation between drawing and cleaning, two modes of attention that operate with some care on architecture and that yet might now be a passing figment of the cleaner's imagination. 


\section{REFERENCES}

Bêka, I., Lemoîne, L. (2008).

Koolhaas Houselife. Film.

Retrieved from https://www.

youtube.com/watch?v=5TOVG

V8 DaMA\&list=RD5TOVGV8D

aMA\#t $=1$

Cheatle, E. (2012). Recording

the absent inside the Maison de Verre. IDEA Journal 2012, 98-111.

Cixous, H. (1991). The last painting or the portrait of God. In D.

Jenson (Ed.), "Coming to writing" and other essays (S. Cornell, A.

Liddle, S. Sellers, S. Suleiman, Trans.) (pp. 104-131). Cambridge, MA: Harvard University Press.

Cixous, H., Heathfield, A. (2010).

Writing not yet thought: Hélène

Cixous in conversation with

Adrian Heathfield. Film direction, camera and editing, Hugo

Glendinning, Retrieved from http://www.adrianheathfield.net/ project/writing-not-yet-thought/

Cixous, H. (2012). Poetry

in painting: Writing on contemporary arts and aesthetics, Edinburgh: Edinburgh University Press.

Colomina, B., Blanca L. (1998). A machine was its heart: House in Floriac. Assemblage 37, 36-45.

Deleuze, G. Guattari, F. (1987). A thousand plateaus: Capitalism and schizophrenia, vol. 2 (B. Massumi, Trans.). Minneapolis, MN \& London, UK: University of Minnesota Press.

Funda, E. (1994). Review of the home plot: Women, writing and domestic ritual. Great Plains Quarterly, Retrieved from http://digitalcommons. unl.edu/cgi/viewcontent. cgi?article $=1820 \&$ context $=$ greatplainsquarterly

Kristeva, J. (1981). Women's time (A. Jardine, Trans.). Signs 7, 5-25.

Kristeva, J. (1982). Powers of horror: An essay on abjection (L. Roudiez, Trans.). New York, NY: Columbia University Press.

Ventura, S. (2009). Being stuck: Between reality and fiction, Log 16, 142-151. 